\title{
Migration and Mental Health: Evidence from a Natural Experiment
}

Steven Stillman, David McKenzie, and John Gibson

BREAD Working Paper No. 123

June 2006

(C) Copyright 2006 Steven Stillman, David McKenzie, and John Gibson
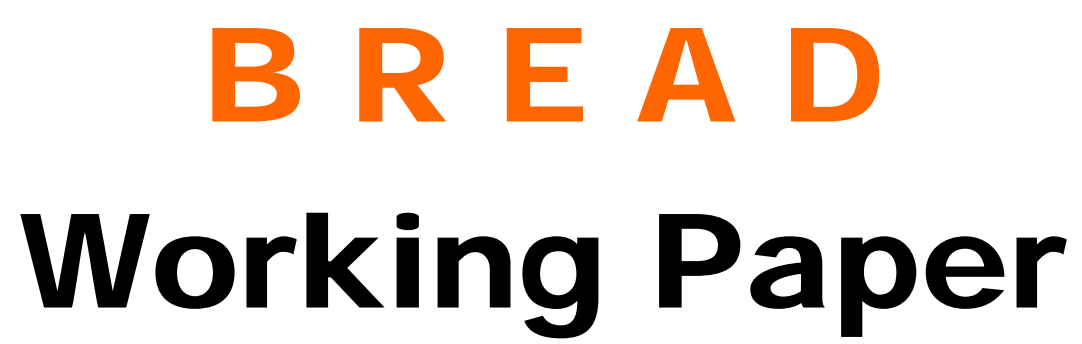

Bureau for Research and Economic Analysis of Development 


\title{
Migration and Mental Health: Evidence from a Natural Experiment ${ }^{1}$ \\ Steven Stillman, Motu Economic and Public Policy Research ${ }^{*}$ \\ David McKenzie, Development Research Group, The World Bank \\ John Gibson, University of Canterbury
}

March 2006

\begin{abstract}
People migrate to improve their well-being, whether through an expansion of economic and social opportunities or a reduction in persecution. Yet a large literature suggests that migration can be a very stressful process, with potentially negative impacts on mental health reducing the net benefits of migration. However, to truly understand the effect of migration on mental health one must compare the mental health of migrants to what their mental health would have been had they stayed in their home country. The existing literature is not able to do this and typically settles for comparing the mental health of migrants to that of natives in the destination country, which takes no account of any pre-existing differences between these groups. This paper overcomes the selection problems affecting previous studies of the effect of migration on mental health by examining a migrant lottery program. New Zealand allows a quota of Tongans to immigrate each year with a lottery used to choose amongst the excess number of applicants. A unique survey conducted by the authors in these two countries allows experimental estimates of the mental health effects of migration to be obtained by comparing the mental health of migrants who were successful applicants in the lottery to the mental health of those who applied to migrate under the quota, but whose names were not drawn in the lottery. Migration is found to lead to improvements in mental health, particularly for women and those with poor mental health in their home country.
\end{abstract}

Keywords: Migration, Mental Health, Natural Experiment

JEL codes: J61, I12, F22

\footnotetext{
${ }^{1}$ We thank the Government of the Kingdom of Tonga for permission to conduct the survey there, the New Zealand Department of Labour Immigration Services for providing the sampling frame, Halahingano Rohorua and her assistants for excellent work conducting the survey, and most especially the survey respondents. Mary Adams and participants at the PAA conference provided helpful comments. Financial support from the World Bank, Stanford University, the Waikato Management School and Marsden Fund grant UOC0504 is gratefully acknowledged. The study was approved by the multi-region ethics committee of the New Zealand Ministry of Health. The views expressed here are those of the authors alone and do not necessarily reflect the opinions of the World Bank, the New Zealand Department of Labour, or the Government of Tonga.

* Corresponding author: E-mail: stillman@motu.org.nz. Address: Motu Economic and Public Policy Research, Level 1, 93 Cuba St., Po Box 24390, Wellington, New Zealand. Phone: 64-4-939-4250 , Fax 64-4-939-4251.
} 


\section{Introduction}

People migrate to improve their well-being, whether through an expansion of economic and social opportunities or a reduction in persecution. Yet, a large literature suggests that migration can be a very stressful process, with potentially negative impacts on mental health. To the extent that these mental health changes reduce the net benefits of migration they are of potential interest to economists, especially because there are strong economic arguments for increasing international migration (World Bank, 2005).

To truly understand the effect of migration on mental health one must compare the mental health of migrants to what their mental health would have been had they stayed in their home country. The existing literature is not able to do this and typically settles for comparing the mental health of migrants to that of natives in the destination country, which takes no account of any preexisting differences between these groups. Even where comparisons are made between movers and stayers from the same country (e.g., Ödegaard, 1932), they have not been able to take account of potential selection biases. These biases will occur if unobserved characteristics that increase the propensity to migrate are also associated with either higher or lower risks of mental health disorders.

This paper overcomes the selection problems affecting previous studies of the effect of migration on mental health by examining a migrant lottery program. The Pacific Access Category (PAC) under New Zealand's immigration policy allows an annual quota of Tongans to migrate to New Zealand in addition to those approved through other migration categories as skilled migrants and family streams. Many more applications are received than the quota allows, so a lottery is used 
by the New Zealand Department of Labour to randomly select from amongst the registrations. A unique survey conducted by the authors in these two countries allows experimental estimates of the mental health effects of migration to be obtained by comparing the mental health of migrants who were successful applicants in the lottery to the mental health of those who applied to migrate under the quota, but whose names were not drawn.

The results show large positive effects of migration on mental health, especially for women and for individuals with low mental health. Thus, rather than there being a mental health cost offsetting some of the economic gains from migration in an overall welfare assessment, these results suggest that migration brings positive benefits beyond economic gains. However, there are at least two caveats to the results. First, the migrants studied here have lived in New Zealand as permanent residents for less than three years and it may be that mental health disorders develop over a longer period (Bhugra, 2004). Second, there appear to be low levels of mental health in Tonga, related especially to employment concerns (UNICEF, 2001), ${ }^{2}$ while the migrants entered a New Zealand labor market that was unusually strong (the lowest unemployment rate in the OECD). Migrants in other settings may not encounter such large improvements in economic opportunities and consequently migration may have less a positive impact on mental health.

The only other paper that we are aware of that considers selection bias in the context of the mental health consequences of migration is Mark, Fu and Tran (2006). These authors compare

\footnotetext{
${ }^{2}$ According to a UNICEF study, one-third of school age youth in Tonga reported experiencing severe sadness or depression in the previous six months. Almost one half of the sample felt it was unlikely or impossible that they would find a job upon leaving school (UNICEF, 2001).
} 
three samples of Vietnamese: immigrants in the United States, non-migrants in Vietnam, and returnees in Vietnam who initially made it to a country of first asylum but were then repatriated because they could not prove a bona fide risk of persecution in Vietnam. This research strategy relies on two comparisons: the first is of returnees with non-migrants to estimate selection effects (due to the unobserved characteristics that increase the propensity to migrate). The second comparison is of immigrants with returnees, which they expect will show migration effects net of selection. However, the flaw with this research design is that forced repatriation is likely to have its own negative effect on mental health. Consequently the returnees are unlikely to be a valid control for what the mental health of the immigrants would have been had they never left Vietnam.

The next section summarizes the findings of existing literature on migration and mental health. Section 3 describes the survey and the MHI-5 measure of mental health used in this study. Section 4 provides a description of patterns of mental health within Tonga, while Section 5 calculates the treatment effect of migration on mental health. Section 6 explores the mechanisms underlying the gain in mental health from migration, while Section 7 concludes.

\section{Previous Literature}

Since the classic study of Ödegaard (1932), which found higher hospital admission rates for schizophrenia among Norwegians who had migrated to the United States than those who stayed in Norway, it has been generally presumed in the literature that migration is harmful for mental health. For example, according to Pernice et al, (2000, p. 24) 
"the adverse effects on mental health of migration have been widely researched and established".

Much of the clinical literature concentrates on schizophrenia, where five hypotheses are suggested for the apparently high incidence rates amongst migrants (Cochrane and Bal, 1987):

1. sending countries have high rates of schizophrenia,

2. schizophrenia predisposes people to migrate,

3. the process of migration produces stress and elevated rates of schizophrenia,

4. certain cultural practices of migrant groups get misdiagnosed as schizophrenia, and

5. some symptoms of schizophrenia are more common amongst the cultures that migrants are from.

There is debate about the strength of each of these hypotheses. According to Bhugra (2004), there is no evidence that either schizophrenia or its symptoms are more prevalent in migrant source countries and cultures. The fact that second generation migrants have higher rates of schizophrenia than their parents also counts against this and against the selection hypothesis that schizophrenics are more likely to migrate. It is also unlikely that stress during the process of migration is a direct cause of mental health disorders because the increased risk of schizophrenia occurs 10-12 years after migration (Bhugra, 2004a). There are also doubts about the evidence for misdiagnosis (Bhugra, 2004).

The evidence is further clouded when attention switches from clinical conditions like schizophrenia to more common mental disorders. According to both Cochrane and Stopes-Roe (1981) and Nazroo (1997) immigrants from South Asia in the United Kingdom had lower rates of emotional disorders and depression than did native-born whites. Similarly, a study of a 
Vietnamese refugee community who had been resettled in Australia for approximately 11 years found that they had only one-third the level of anxiety and mood disorders when compared with the host population (Steel et al, 2005). This same refugee community had initially high rates of disorder in the immediate post-migration period, indicating that timing effects and acculturation may be important.

Studies of the mental health of immigrants in New Zealand reveal the same ambiguity present in the international literature. These studies either compare samples of immigrants with the general New Zealand population or compare amongst different immigrant groups according to their country or region of origin. Information on both pre-migration mental health and on the mental health of non-migrants from the source country is lacking and non-random convenience samples are typically used. Hence, these studies are not able to provide a reliable answer to the question posed here: "what is the effect of migration on mental health".

However the presumption from most of these studies is that the mental health of immigrants is likely to suffer, if not due to migration per se then due to additional risk factors experienced post-migration. According to a recent review:

"Whereas migration does not inevitably result in mental health problems, failure to find employment, language difficulties, separation from family and community, and traumatic experiences prior to migration have been identified as factors associated with increased risk of mental disorder” (Ho, 2004, p. 45).

Pernice and Brook (1994) find the mental health of a sample of 57 Pacific Island immigrants in New Zealand to be as low as that of a sample of 129 Southeast Asian refugees, and significantly 
lower than that of 63 British immigrants. ${ }^{3}$ The comparatively poor mental health of the Pacific Islanders may be due to their experience of discrimination and unemployment, which were amongst the most significant correlates of mental disorders for the pooled sample (Pernice and Brook, 1996). Amongst both the Southeast Asian refugees and Pacific Island migrants, 30 percent of respondents reported experiencing discrimination in either their workplace or from health professionals. Amongst the Pacific Island migrants, 40 percent of those experiencing significant emotional distress were unemployed. Once employment was controlled for there was no significant effect of income on mental health. Demographic characteristics and length of time in New Zealand (which averaged four years) were also insignificant influences.

Pernice, Trlin, Henderson and North (2000) use the General Health Questionnaire (GHQ-12) on a convenience sample of 107 skilled immigrants from China, India, and South Africa. There were no differences in mental health amongst these immigrants in terms of their employment status, length of time in New Zealand (which averaged less than one year) and origin country. Abbott, Wong, Williams, Au and Young (1999) also use the GHQ-12, but with a postal survey of 271 ethnic Chinese migrants living in Auckland. Amongst the recent ( $<2$ years) arrivals, those who were unemployed in New Zealand but had been employed in their origin country had worse mental health than those whose employment status did not change. Also, those who were younger, who could not read English, and who were female also had poorer mental health. ${ }^{4}$

\footnotetext{
${ }^{3}$ Based on the 25-item Hopkins Symptom Checklist, which focuses on anxiety and depression clusters of questions. ${ }^{4}$ Many of the women in the sample were from so-called 'astronaut families' who had absent husbands still working in the origin country while the wives and children were fulfilling residency requirements in New Zealand.
} 
In contrast to these negative conclusions about the effect of migration on health, one of the earliest and most robust studies in New Zealand concluded that Pacific Island migrants were facing fewer mental health problems than were European New Zealanders (but this study did not cover the pre-migration health of the Pacific Islanders). Graves and Graves (1985) surveyed 228 Samoans, 212 Cook Islanders and 224 native-born New Zealanders of European background. These were random samples from three working class neighborhoods in Auckland, stratifying by city block. The Pacific Islanders had significantly fewer psychosomatic symptoms of health problems than did the European New Zealanders:

In general, despite substantial disadvantages in terms of background experience, and training and a larger number of dependent family members to support, Pacific Island immigrants to New Zealand [...] reported fewer health problems than the European sample: for example, they are significantly less likely to display the psychological tensions and pressures which manifest themselves in the form of insomnia, nervousness and a variety of little accidents” (Graves and Graves, 1985, p.15).

\section{Measuring Mental Health/the PINZMS Data}

The data used in this paper are from the Tongan component of the Pacific Island-New Zealand Migration Survey (PINZMS), a comprehensive household survey designed to measure multiple aspects of the migration process. This survey includes questions on household demographics, education, labor supply, income, asset ownership and food consumption, based where possible on the most widely used surveys in New Zealand and the Pacific Islands to enhance comparability. The survey pays special attention to health issues, relying on both self-reported information (overall self-rated health and its change, use of health facilities, smoking and 
drinking behavior, hypertension and diabetes histories) and anthropometric measurements (blood pressure, height, weight and girth).

The mental health questions use the Mental Health Inventory 5 (MHI-5) of Veit and Ware (1983). ${ }^{5}$ This is a five item scale with a maximum score of 25 and minimum score of 5 . Higher scores are desirable in that they indicate the experience of psychological well-being and the absence of psychological distress during the past month. The MHI-5 measure was developed for use in the general population and has been used as part of general surveys of health and quality of life in addition to specific studies on mental health. The measure compares well to other more detailed measures. For example, Berwick et al. (1991) compared the screening accuracy of the MHI-5 with that of the longer 18-item MHI, the 30-item version of the General Health Questionnaire (GHQ-30), and a 28-item Somatic Symptom Inventory (SSI-28). The MHI-5 was found to be as good as the MHI-18 and the GHQ-30, and better than the SSI-28, for detecting major depression, general affective disorders, and anxiety disorders

The unique feature of the PINZMS survey is that it has a mechanism that allows selection biases to be overcome. New Zealand has a special immigration category, established in 2001, called the Pacific Access Category (PAC), which allows an annual quota of 250 Tongans to migrate to New Zealand without going through the usual migration categories used for groups such as skilled migrants and business investors. ${ }^{6}$ Specifically, any Tongan citizens aged between 18 and

\footnotetext{
${ }^{5}$ We use version 2, which is the mental health component of the 36 item short-form health survey (SF-36) which has been used in over 50 countries as part of the International Quality of Life Assessment project (http://www.sf36.org). Appendix 1 lists the specific questions used in the MHI-5.

${ }^{6}$ The Pacific Access Category also provides quotas for 75 citizens from Kiribati, 75 citizens from Tuvalu, and 250 citizens from Fiji to migrate to New Zealand.
} 
45, who meet certain English, health and character requirements, ${ }^{7}$ can register to migrate to New

Zealand. ${ }^{8}$ Many more applications are received than the quota allows, so a ballot is used by the

New Zealand Department of Labour (DoL) to randomly select from amongst the registrations.

Once their ballot is selected in the lottery, applicants must then provide a valid job offer in New

Zealand within six months in order to have their application to migrate approved and be allowed to migrate.

The survey design and enumeration, which was overseen by the authors in the first half of 2005, covered random samples of four groups: (i) Tongan migrants to New Zealand, who were successful participants in the 2002/03 and 2003/04 PAC lotteries, (ii) successful participants from the same lotteries who were still in Tonga, either because their application for New Zealand residence was not approved (typically because of lack of a suitable job offer) or was still being processed, (iii) unsuccessful participants from the same lotteries who were still in Tonga, and (iv) a group of non-applicants in Tonga. ${ }^{9}$

\footnotetext{
${ }^{7}$ Data supplied by the DoL for residence decisions made between November 2002 and October 2004 reveals that out of 98 applications, only 1 was rejected for failure to meet the English requirement, and only 3 others were rejected for failing other requirements of the policy.

${ }^{8}$ The person who registers is a Principal Applicant. If they are successful, their immediate family (spouse and children under age 18) can also apply to migrate as Secondary Applicants. The quota of 250 applies to the total of Primary and Secondary Applicants, and corresponds to about 70 migrant households.

${ }^{9}$ The initial sample frame for groups (i) and (ii) was a list of the names and addresses of the 278 (out of almost 3000 applicants) successful participants in the 2002/03 and 2003/04 migration lotteries, which was supplied under a contractual arrangement with the New Zealand Department of Labour, with strict procedures used to maintain the confidentiality of participants. Approximately 100 of these successful ballots had been approved for residence in New Zealand by the time of the survey, although some of those families had not yet moved to New Zealand. We managed to locate 65 of the families that had migrated, giving a sampling rate of over 70 percent, and drew a random sample of 55 of the successful ballots that had not yet migrated. This non-migrant group includes those whose applications were rejected and those whose applications were still being processed. We use the actual number of accepted and rejected applications to weight our sample. The initial sample frame for the unsuccessful ballots (group (iii)) was a list of names and addresses provided by the DoL. We derived a sample of 78 unsuccessful ballots from this information, implicitly stratifying by island and by the village of residence when the applicant entered the ballot. The sample of non-applicants was obtained by selecting 60 households, with at least one member aged 18 to 45 , in either the same villages that the migrants had been living in prior to migrating or in the same villages that unsuccessful ballots were found in. The interviewer for all the migrant households in New Zealand also interviewed
} 
The probability of success in these ballots was approximately $10 \%$. Thus, we have a group of migrants and a comparison group who are similar to the migrants, but remain in Tonga only because they were not successful in the lottery. This allows experimental estimates of the mental health effects of migration to be obtained by comparing the mental health of migrants who were successful applicants in the lottery to the mental health of those who applied to migrate under the quota, but whose names were not drawn in the lottery.

The other options available for Tongans to migrate are fairly limited, unless they have close family members abroad. Ninety-four percent of all Tongan migrants are located in New Zealand, the United States and Australia. ${ }^{10}$ In the 2004/05 financial year New Zealand admitted 1482 Tongans, of which 58 entered through a business/skilled category, 549 through family sponsored categories and 749 through the Pacific Access Category. ${ }^{11}$ Australia admitted 284 Tongans during the same financial year. ${ }^{12}$ The United States admitted 324 Tongans in the 2004 calendar year, comprising only 5 under employment-based preferences and 290 under immediate relative or family-sponsored categories. ${ }^{13}$ Thus, the PAC accounted for $42 \%$ of all migration to these three countries, and over $90 \%$ of non-family category migration.

about one-half of the households from the three samples in Tonga, reducing one potential source of extraneous variation between the samples. Interviewer effects on the mental health scores are discussed below.

${ }^{10}$ Source: GTAP database of Parsons et al. (2005).

${ }^{11}$ Source: Residence Decisions by Financial Year datasheet provided by New Zealand Department of Labour. Note that the high number of PAC approvals in the 2004/05 financial year reflects backlog from prior PAC ballots which were not approved until this time.

${ }^{12}$ Source: Settler Arrivals 2004-2005, Australian Government Department of Immigration and Multicultural Affairs.

${ }^{13}$ Source: 2004 Yearbook of Immigration Statistics, U.S. Department of Homeland Security Office of Immigration Statistics. 


\section{Mental Health Patterns in Tonga}

We begin by using the samples taken in Tonga to examine the correlates of mental health status in Tonga. These results will then be used later in the paper as an aid to help understand the possible channels through which migration may be affecting mental health. Table 1 presents the results of regressing the MHI-5 score on socioeconomic characteristics of the respondents. These regressions are used merely to describe the patterns present in the data, since variables such as education, labour force status, religion, and physical health, which are used as regressors, may themselves be affected by mental health status.

Column 1 presents a base regression, relating mental health status to some of the most common correlates studied in the literature. Mental health is seen to be significantly higher for females than males. While this is in contrast to the patterns found in many other countries, it is consistent with previous evidence from Tonga, at least amongst school-age youth (UNICEF, 2001). Mental health declines with age up until age 52, after which it starts increasing again. As all applicants to the migration lottery we study must be aged 45 or below, this means that mental health is declining with age among the eligible age range for migration. Mental health status is found to be lower for individuals born on the main island of Tongatapu compared to those born on the other islands in Tonga. Most importantly for assessing the impact of migration on mental health, we see a positive association between household income and mental health, and between employment and mental health. A one standard deviation increase in monthly household labour income is associated with a 0.34 increase (or 0.15 standard deviation) increase in mental health and being employed is associated with a 0.37 (or 0.16 standard deviation) increase in mental health. 
Columns 2 through 4 of Table 1 then consider the relationship with additional factors. Column 2 shows that being Catholic is associated with higher mental health than other denominations. Column 3 adds several measures of physical health status and health behavior. Individuals who report their health status as very good (as compared to good, average, bad or very bad) have higher mental health, but not significantly so. Smokers have lower mental health than nonsmokers, while binge drinking has no significant or sizeable relationship with mental health. Column 4 shows that adding a quadratic term in household labour income does not significantly improve the fit of the regression, and so we stick with a linear income term for the remaining columns. $^{14}$

Columns 5 and 6 of Table 1 then estimate the correlates of mental health separately by sex. Most of the variables have similar relationships with mental health for males and females. In particular, a 100 pa'anga increase in monthly household labour income is associated with a 0.11 increase in mental health for men and a 0.12 increase in mental health for women. In contrast, being employed is associated with a stronger effect on mental health for women than for men. Smoking is associated with lower mental health for men than for women. In Column 7, we therefore re-estimate the regression by pooling sexes, but allowing for interactions between gender and employment status, and gender and smoking. This shows being employed to be significantly associated with better mental health status for females, but not for males.

\footnotetext{
14 Total household labour income also led to a better fit than using either log(income/100+1) or per capita household labour income. Adding one pa'anga to household labour income is done to allow taking logarithms of income for households which report zero labour income.
} 


\section{The Effect of Migration on Mental Health}

\subsection{Estimating treatment effects using experimental data}

The remainder of this paper focuses on estimating the impact of migration to New Zealand on the mental health of Tongans. To determine the impact of migration on mental health, one must compare the mental health of the migrant to what their mental health would have been like had they not migrated. Typically, it is not possible to readily identify this unobserved counterfactual outcome. However, the PAC lottery system, by randomly denying eager migrants the right to move to New Zealand, creates a control group of individuals that should have the same outcomes as what the migrants would have had if they had not moved. As can be seen in Table 2, which compares the means of ex-ante characteristics for lottery winners and lottery losers among all individuals age 15 and above in our sample and finds that we can not reject equality of means for any of the variables, the random selection of ballots among applicants in the PAC lottery provides a control group of non-migrants that are statistically identical to the migrants in our sample.

Table 3 presents the mean mental health score and the proportion of individuals self-reporting very good health, as opposed to good or average health, among the different groups in our sample. The mean mental health score among migrants is 21.9, compared to 19.5-19.9 for applicants to the PAC lottery who did not migrate, and 20.5 among all individuals aged 15 and above who are either the head of household, spouse of the head of household, or a child of the head of household in non-applicant households. A t-test of equality of means strongly rejects the null hypothesis of equality of migrant mental health with any of the other groups. Similar results are found for self-reported health status, with 58.6 percent of migrants reporting very good 
health, compared to 32.4-36.2 percent of non-migrant applicants, and 37.7 percent of nonapplicants. Again, a t-test of equality of means strongly rejects the null hypothesis of equality of migrant self-reported health status with any of the other groups.

A comparison of mean mental health for lottery winners who migrate and lottery losers can be used to obtain an experimental measure of the impact of migration on mental health. This simple comparison of means at the bottom of Table 3 shows migration leads to an increase in mental health score of 1.98 (and a 22 percentage point increase in likelihood of reporting very good health). As discussed in Heckman et. al. (2000), this simple experimental estimator of the treatment effect on the treated (SEE-TT) is biased if control group members substitute for the treatment with a similar program or if treatment group members dropout of the experiment.

In our application, substitution bias will occur if PAC applicants who are not drawn in the lottery migrate to New Zealand through an alternative visa category such as the family or skills category or migrate to another country and dropout bias will occur if PAC applicants whose name are drawn in the lottery fail to migrate to New Zealand. We do not believe that substitution bias is of serious concern in our study, as individuals with the ability to migrate via other arrangements will likely have done so previously given the low odds of winning the PAC lottery. ${ }^{15}$ However, as shown in Table 3, dropout bias is a more relevant concern; only one-third of lottery winners had migrated to New Zealand at the time of our survey. A number of the other individuals are in

\footnotetext{
${ }^{15}$ We did not come across any incidences where remaining family members told us that the unsuccessful applicant had migrated overseas during our fieldwork.
} 
the process of moving, while others are unable to move due to the lack of a valid job offer in New Zealand for the household principal applicant. ${ }^{16}$

Given that not all lottery winners have migrated, the SEE-TT estimator will give a consistent estimate of the impact of migration on mental health if and only if there is no selection as to who migrates among those successful in the lottery. This condition does not seem likely to hold, and we therefore turn to other estimation methods.

\subsection{Intention-to-treat effect}

Experimental data, in the presence of substitution and dropout bias, can identify the mean impact of a program (eg. winning the lottery) on outcomes (eg. mental health), also known as the intention-to-treat effect (ITT). ${ }^{17}$ This estimator is unbiased by virtue of the randomization of lottery winners and losers and can be computed by comparing the mean mental health for ballot winners to that for ballot losers. As shown at the bottom of Table 3, on average, winning the PAC lottery is estimated to increase mental health by 0.40 points.

While the results in Table 2 show that the lottery did indeed achieve reasonably comparable groups, the small size of our sample may have resulted in some differences between successful and unsuccessful ballots. To improve the efficiency of our ITT estimate, we add variables which

\footnotetext{
${ }^{16}$ Lottery winners have six months to lodge a formal residence application containing evidence of a job offer. It then typically takes three to nine months for applicants to receive a decision on their application, after which those who are approved have up to one year to move. Relatively few applications are rejected due to lack of a valid job offer, but lack of a job offer prevents many lottery winners from lodging residence applications.

${ }^{17}$ The terminology Intent-to-treat comes from the medical literature, and refers to analysis based on the original random assignment of individuals to treatment or control groups, regardless of whether or not individuals actually received or complied with the treatment. In our context, it gives the impact of assignment to migration status through the lottery, regardless of whether individuals who win the lottery actually migrate or not.
} 
control for the observable pre-existing characteristics of the two groups and estimate $\beta$ in the following regression:

MentalHealth $_{\mathrm{i}}=\alpha+\beta^{*}$ BallotSuccess $_{\mathrm{i}}+\delta^{\prime} \mathrm{X}_{\mathrm{i}}+\omega_{\mathrm{i}}$

Column 1 of Table 4 first estimates this regression with no controls, repeating the estimate of 0.40 obtained as the difference in means. The regression model indicates that this impact is statistically insignificant. In Column 2, we add a set of controls for pre-existing characteristics of individuals. These include standard variables, such as age, sex, marital status, and years of education. In addition, we include height as a pre-existing measure of health, whether or not the individual was born on the main island of Tongatapu, and dummy variables indicating the individual's religion (Catholic v. Mormon v. Protestant v. Other), and past income to capture the effect of a host of unobserved individual attributes. Adding these controls increases the size of the estimated effect only slightly, to 0.44 , which is not significantly different from either the estimate obtained without controls or from zero.

\subsection{Average treatment effects}

These unbiased estimates of the ITT are substantially smaller than the biased estimate of the SEE-TT both because many individuals in the treatment group actually fail to receive the treatment (eg. migrate) and because of the potential dropout bias arising from non-random migration among those who do win the lottery. Instrumental variables provide an approach for estimating average treatment effects with experimental data. In our application, the PAC lottery outcome can be used as an excluded instrument because randomization ensures that success in the lottery is uncorrelated with unobserved individual attributes which might also affect mental health and success in the lottery is strongly correlated with migration (the first stage F-statistic is 
47.7). ${ }^{18}$ This estimate is called the local average treatment effect (IV-LATE) and can be interpreted as the effect of treatment on individuals whose treatment status is changed by the instrument. Angrist (2004) demonstrates that in situations where no individuals who are assigned to the control group receive the treatment (eg. there is no substitution) then the IV-LATE is the same as the average treatment effect on the treated (IV-TT).

Column 3 of Table 4 reports the IV-TT estimator when no other controls are included in the regression model, and estimates a 1.19 point increase in mental health from migrating, which is a large, but statistically insignificant impact. Column 4 then adds the same control variables used above when estimating the ITT; the estimated impact increases slightly to 1.31 points, but is still statistically insignificant. ${ }^{19}$ In Columns 5 and 6 of Table 4, we examine whether the treatment effect of migration differs for males and females. The estimated impact is found to be twice as large for females as for males (1.8 for females compared to 0.9) for males, with the female effect statistically significant at significance levels of 7 percent or higher. However, given the large standard errors, one can not reject equality of the effect for males and females.

These results suggest that, on average, migration to New Zealand has a large positive impact on the mental health of Tongans, with possibly larger effects for women. Figure 1 displays kernel density estimates in the top graphs and actual cumulative densities in the bottom graphs of the

\footnotetext{
${ }^{18}$ Validity of the instrument also requires that the lottery outcome does not directly affect mental health conditional on migration status. One could conceive of stories such as that winning the lottery and not being able to migrate causes frustration which leads to a decline in mental health, or conversely, winning the lottery impacts mental health by causing adulation or worries about the prospect of migrating. However, as is seen in Table 4, the mental health of non-migrants among the successful ballots is very similar to that of the unsuccessful ballots giving us reason to believe that the instrument is a valid one.

${ }^{19}$ We also experimented with adding interviewer fixed effects. While these were statistically significant, they had no qualitative effect on the estimated average treatment effect, changing it from 1.31 (with a standard error of 0.91) to 1.38 (standard error of 1.08).
} 
mental health scores of men (left column) and women (right column) among migrants, nonmigrant ballot winners, and ballot losers. These figures show that the impact of migration on mental health appears to be strongly non-linear. While the mental health of non-migrants is distributed fairly normally (and is similar for non-migrants with both successful and unsuccessful ballots ${ }^{20}$ ), the mental health of migrants is strongly modal and skewed towards the upper part of the mental health distribution. ${ }^{21}$ This suggests that a more promising approach might be to estimate models that allow for non-linear treatment effects.

\section{Figure 1}
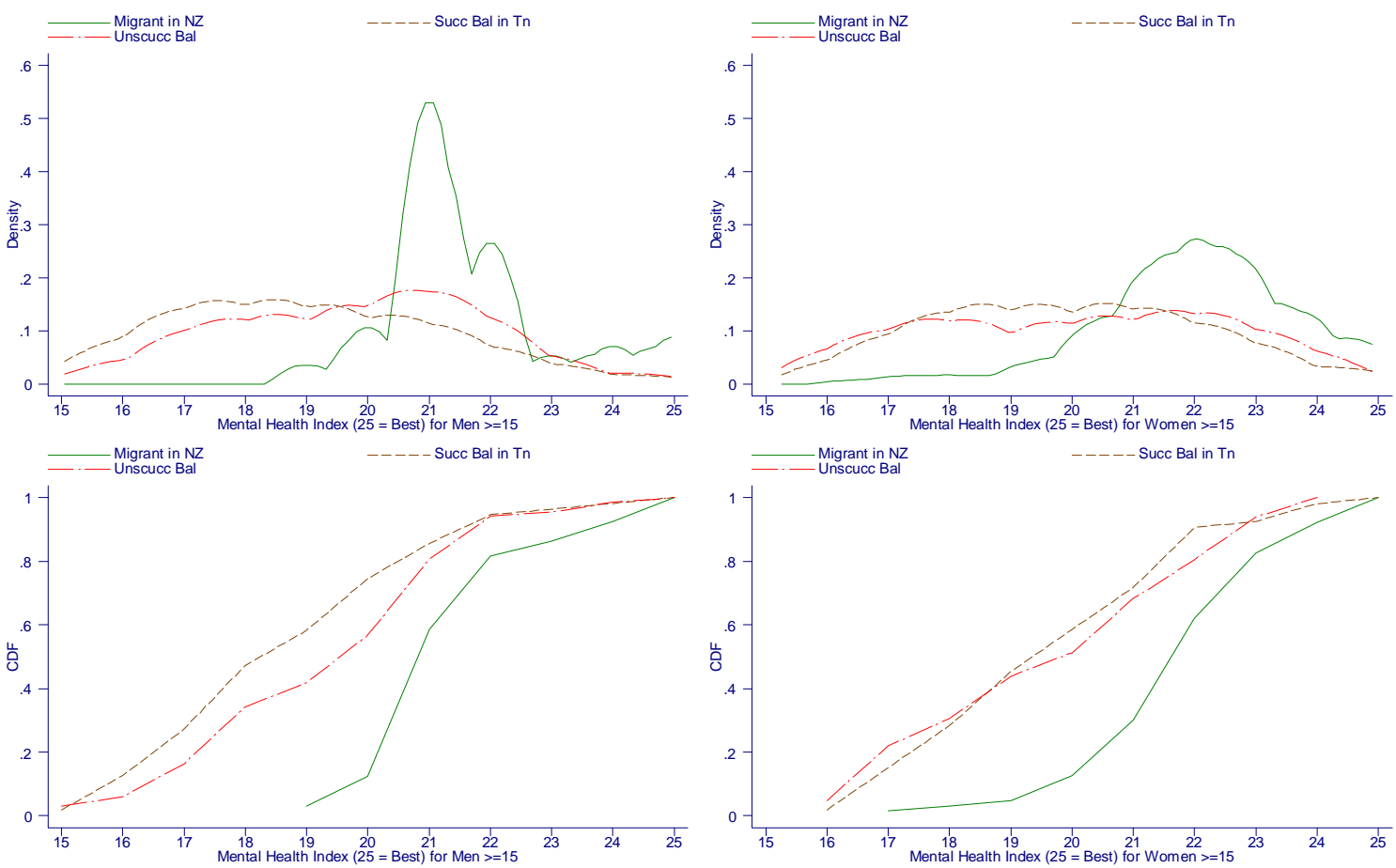

\section{Mental Health by Gender}

\footnotetext{
${ }^{20}$ One can see that the distribution of mental health for non-migrant females is very similar among lottery winners and losers, while males in households which win the lottery but do not migrate have a distribution which is slightly to the left of that of males in non-lottery winner households.

21 The difference in the densities of the mental health distribution of migrants and the lottery losers is highly significant. Davidson-Duclos tests of stochastic dominance reveal that the migrant distribution first-order stochastically dominates that of the lottery loser group.
} 


\subsection{Non-linear treatment effects}

We take two approaches to estimating non-linear treatment effects. First, we examine the impact of migration on the probability of having a mental health score below various thresholds. The rationale for this is that we might expect improvements in mental health to only occur for individuals who would have poor mental health in the absence of migration. Individuals who are already happy and suffer from no signs of mental distress may not see improvements in mental health. This is clearly true in mechanical matter at the very top of the distribution, but may also occur for the individuals in the upper-middle of the distribution.

Different thresholds correspond to different degrees of mental distress. While there is no universal choice of a threshold, several studies of general populations have used a cut-off of less than 17 as an indicator of major depression, and a cut-off of less than 19 as an indicator of poor mental health (Urban Institute, 1999; Yamazaki et al, 2005). ${ }^{22}$ In our non-migrant sample, 4.9\% of individuals have scores less than 17, $15.6 \%$ have scores below 18, $26.6 \%$ have scores below 19, and 38.8\% have scores below 20. However, in the migrant sample, the lowest observed mental health score is 17 , and so estimation is only possible for thresholds above this. We therefore estimate the likelihood of having a mental health score less than 18, less than 19, and less than 20 using an instrumental variable maximum likelihood probit model where whether an individual has migrated to New Zealand is instrumented by whether their household was successful in the PAC lottery.

\footnotetext{
${ }^{22}$ These studies scale the MHI-5 to a 0-100 scale, and use thresholds of 56 for depression and 67 for general poor mental health, which we convert back to numbers on the 5-25 scale.
} 
These results are presented in Table 5. The same covariates are included in the regression as when estimating average treatment effects. We find that migrants are 17 percent less likely to have a mental health score less than 18, 31 percent less likely to have a score less than 19, and 37 percent less likely to have a score less than 20. In each case, the impact of migration on mental health is strongly significant.

Second, we follow the methodology of Chernozhukov and Hansen (2005) for estimating quantile treatment effects (QTE) using instrumental variables. We estimate the impact of migration on mental health at the 25th, 50th, and 75th percentile of the mental health distribution. The key assumption of this econometric model is that individual unobservables are rank invariant to the potential treatment status, e.g. individuals who have better (worse) mental health without migrating will also have better (worse) mental health if they migrate. Thus, rank invariance implies that a common unobserved factor, for example, general mental state, determines the ranking of a given person across treatment states.

Table 6 presents the results from this model. For our application, it is necessary to bootstrap standard errors. We present both the standard error of the bootstrapped coefficients and the nonsymmetric 80 percent confidence interval derived from the bootstrapped coefficients. ${ }^{23}$ Consistent with our results on thresholds, treatment effects appear to be larger at the lower part of the mental health distribution. For example, migration increases mental health by 2.81 points for individuals at the 25th percentile of the mental health distribution, but only by $1.05-1.10$

\footnotetext{
${ }^{23}$ The QTE model is estimated using an iterative procedure. We trimmed our bootstrapped coefficients to remove estimates from models that did not properly converge. This lead to the removal of 256 out of 1000 estimates for the 25th percentile, 36 estimates for the 50th percentile, and 15 estimates for the 75th percentile.
} 
points for individuals higher in the distribution. While these results are not statistically significant at conventional levels, the estimate for the 25th percentile is significant at the .053 level using the derived standard error and within the non-symmetric $80 \%$ confidence interval, and the estimate for the 75th percentile is significant within the non-symmetric $80 \%$ confidence interval.

Taken together, these results indicate that the migration improves the mental health of individuals with low mental health scores, thus reducing the overall likelihood of migrants having poor mental health.

\section{Interpreting the Results}

Migration is seen to improve mental health, particularly for women and those with low mental health in the absence of migration. In this section we attempt to understand some of the channels through which this effect operates. As seen in Table 1, mental health status in Tonga is significantly associated with household labor income, employment status, and smoking behaviour, all of which may change with migration. Therefore, in Table 7 we report the ATT effect of migration on these variables, using the lottery outcome as an instrument for migration.

As shown in McKenzie, Gibson and Stillman (2006), migration from New Zealand to Tonga results in large increases in income. Converting New Zealand dollars earned by migrants into Tongan pa'anga for ease of comparison with Table 1, Column 1 shows a 670 pa'anga per month increase in household labour income from migration. Adding several controls in Column 2 does not change this significantly, still giving a 657 pa'anga increase. From Table 1, column 7, we see 
a 100 pa'anga increase in household labour income is associated with a 0.12 increase in mental health. Based on this, we would predict a 0.78 increase in mental health from migration, which is 60 percent of the overall effect found in column 4 of Table 4.

Table 7 shows no overall effect of migration on the probability of being employed, or of smoking. There is also no significant impact on smoking when we look separately by gender. However, when we estimate the effect of migration on employment separately for males and females, males show a positive, but insignificant effect, whereas females have a negative effect which is significant at the 10 percent level. Comparing employment status before and after migration, we see that 37 percent of females who were not employed before migration were employed afterwards, whereas 55 percent of females who were employed before were not employed in New Zealand at the time of interview. In contrast, for males, 88 percent of those not employed before migrating were employed in New Zealand, whereas only 18 percent of those employed in Tonga were not employed in New Zealand. ${ }^{24}$ However, Table 1 shows that employment status is positively associated with mental health for women, but not for men. Hence, if anything, the short-term employment effect of migration should be to lower mental health for women, and so changes in employment can not explain the gain in mental health from migration.

While income can potentially explain the majority of the increase in mental health, based on this analysis, it does not appear to explain the greater increase in mental health for females, and for those with lower mental health in Tonga. It seems plausible that other, possibly non-monetary

\footnotetext{
${ }^{24}$ Note that many of the migrants in our sample had only been in New Zealand for less than one year, so female migrants traveling with their spouse may have still been arranging a job in New Zealand.
} 
factors, may account for these differences. To explore this, we examine questions administered to principal applicants to the migration lottery, for the sample of lottery participants who did not migrate to New Zealand. We asked these potential migrants how important different reasons were for wanting to migrate to New Zealand. In Table 8, we highlight whether there are differences in the motives for migrating for those with lower compared to higher mental health, and for females compared to males. We use a threshold of less than 20 for mental health status to split the sample roughly equally into low and high mental health.

Table 8 does show significant differences in the motives for wanting to migrate between low and high mental health individuals in Tonga, and between men and women. Individuals with low mental health are significantly more likely to say that joining family members in New Zealand, and the desire for a better social life are very important reasons for wanting to migrate; 70 percent of those with mental health score less than 20 say social life is a very important reason, compared to only 35 percent of those with mental health of 20 or higher. In contrast, those with higher mental health are more likely to want to migrate so that their children can attend school in New Zealand. Women are more likely than men to say that joining family members already in New Zealand, accessing better public services such as health care, and being subject to less cultural restrictions are very important reasons for wanting to migrate.

The results in Table 8 therefore suggest that in addition to the income effect, the gain in mental health from migration may arise from the ability of some migrants to join other family members who are already abroad, to have a better social life in New Zealand, access better public services, 
and be subject to less cultural restrictions. That is, it appears likely that there are lifestyle and non-financial factors which improve mental health, as well as the income gain.

\section{Conclusions}

A large literature suggests that migration can be a very stressful process, with potentially negative impacts on mental health. However, to truly understand the effect of migration on mental health one must compare the mental health of migrants to what their mental health would have been had they stayed in their home country. The existing literature is not able to do this and typically settles for comparing the mental health of migrants to that of natives in the destination country, which takes no account of any pre-existing differences between these groups. This paper overcomes the selection problems affecting these previous studies by examining a migrant program which uses a lottery to choose amongst excess number of applicants.

We find that migrants from Tonga to New Zealand experience a gain in mental health, with the gains larger for women and for those with lower levels of mental health in Tonga. This gain in mental health suggests that the overall welfare impact of migration is even larger than that brought about by the large increase in income that migration offers. The analysis in this paper also shows that the impacts of large life changes on mental health can be nonlinear, and so studies of mental health need to look beyond average treatment effects. 


\section{Appendix: MHI-5 Questions}

1. During the past month, how much of the time were you a happy person?

(1=All of the time, $2=$ Most of the Time, $3=$ Some of the time, $4=$ A little of the time, $5=$ None of the time)

2. How much of the time, during the past month, have you felt calm and peaceful?

(1=All of the time, $2=$ Most of the Time, $3=$ Some of the time, $4=$ A little of the time, $5=$ None of the time)

3.How much of the time, during the past month, have you been a very nervous person?

(1=All of the time, $2=$ Most of the Time, $3=$ Some of the time, $4=$ A little of the time, $5=$ None of the time)

4. How much of the time, during the past month, have you felt down-hearted and blue?

(1=All of the time, $2=$ Most of the Time, $3=$ Some of the time, $4=$ A little of the time, $5=$ None of the time)

5.How much of the time, during the past month, did you feel so down in the dumps that nothing could cheer уои ир?

(1=Always, $2=$ Very often, 3=Sometimes, 4=Almost Never, 5=Never)

Questions 1 and 2 are reverse-scored, so that answer one receives score 5, answer two score 4, and so on. Questions 3 through 5 are scored as they appear. This gives a maximum MHI-5 score of 25, and a minimum of 5, with higher scores representing better mental health. 


\section{References}

Abbot, M., Wong, S., Williams, M., Au, M., and Young, W. 1999. Chinese migrants' mental health and adjustment to life in New Zealand. Australian and New Zealand Journal of Psychiatry 33(1): 13-21.

Angrist, J.D. (2004) “Treatment Effect Heterogeneity In Theory and Practice”, Economic Journal 502: C52-C83.

Berwick DM, Murphy JM, Goldman PA, Ware JE Jr, Barsky AJ, Weinstein MC (1991) "Performance of a five-item mental health screening test", Medical Care 29(2): 169-76.

Bhugra D. (2004) “Migration, distress and cultural identity,” British Medical Bulletin 69(1): 129-141.

Bhugra, D. (2004a) “Migration and mental health,” Acta Psychiatrica Scandinavica 109(2): 243-258.

Chernozhukov, Victor and Christian Hansen (2005), “An IV Model of Quantile Treatment Effects,” Econometrica 73(1): 245-261

Cochrane, R., and Bal, S. (1987) "Migration and schizophrenia: an examination of five hypotheses," Social Psychiatry 22(2): 181-191.

Cochrane, R., and Stopes-Roe, M. (1981) "Psychological symptom levels in Indian immigrants to England - a comparison with native English,” Psychological Medicine 11(2): 319-327.

Graves, T. and Graves, N. 1985. Stress and health among Polynesian migrants to New Zealand. Journal of Behavioral Medicine 8(1): 1-19.

Heckman, J., Hohmann, N., Smith, J. and Khoo, M. (2000) "Substitution and Dropout Bias in Social Experiments: A Study of an Influential Social Experiment”, Quarterly Journal of Economics 115(2): 651-694.

Ho, E. 2004. Mental health of Asian immigrants in New Zealand: a review of key issues. Asian and Pacific Migration Journal 13(1): 39- 60.

Mark, V., Fu, H., and Tran, D. 2006. Impact of international migration on mental health outcomes. Poster presented at the Annual Meeting of the Population Association of America Los Angeles, March, 2006.

McKenzie, D., Gibson, J. and Stillman, S. (2006) "How important is selection? Experimental vs non-experimental measures of the income gains from migration”, Mimeo. The World Bank.

Nazroo J. (1997) Ethnicity and Mental Health: Findings from a National Community Survey. Policy Studies Institute, London.

Odegaard, O. (1932) “Emigration and insanity,” Acta Psychiatrica et Neurologica 4(1): 1-206

Parsons, Christopher, Ronald Skeldon, Terrie Walmsley and L. Alan Winters (2005) "Quantifying the International Bilateral Movements of Migrants”, Mimeo. The World Bank and the Development Research Centre on Migration, Globalisation and Poverty at Sussex University.

Pernice, R. and Brook, J. 1994. Relationship of migrant status (refugee or immigrant) to mental health. International Journal of Social Psychiatry 40(3): 177-188.

Pernice, R. and Brook, J. 1996. Refugees' and immigrants' mental health: association of demographic and post-immigration factors. The Journal of Social Psychology 136(4): 511-519. 
Pernice, R. Trlin, A., Henderson, A., and North, N. 2000. Employment and mental health of three groups of immigrants to New Zealand. New Zealand Journal of Psychology 29(1): 24-29.

Steel Z., Silove D., Chay T., Bauman A., Phan T., and Phan T. (2005) "Mental disorders, disability and health service amongst Vietnamese refuges and the host Australian population,” Acta Psychiatrica Scandinavica 111(4): 300-309

Urban Institute (1999) "Snapshots of America's Families: Appendix", http://www.urban.org/url.cfm?ID=900875

UNICEF (2001) The State of Health Behaviour and Lifestyle of Pacific Youth. Kingdom of Tonga Report. UNICEF Pacific. Suva, Fiji.

Veit, C.T. \& Ware, Jnr, J.E. (1983). "The structure of psychological distress and well-being in general populations”, Journal of Consulting and Clinical Psychology, 51, 730-742

World Bank (2005) Global Economic Prospects: Economic Implications of Remittances and Migration World Bank Group, Washington DC.

Yamazaki, S., S. Fukuhara and J. Green (2005) "Usefulness of five-item and three-item Mental Health Inventories to screen for depressive symptoms in the general population of Japan”, Health and Quality of Life Outcomes 3/1/48 
TABLE 1: PREDICTORS OF MENTAL HEALTH STATUS IN TONGA

\begin{tabular}{|c|c|c|c|c|c|c|c|}
\hline & (1) & (2) & (3) & (4) & $(5)$ & $(6)$ & (7) \\
\hline & All & All & All & All & Males & Females & All \\
\hline \multirow[t]{2}{*}{ Female Dummy } & $0.307^{*}$ & $0.331^{*}$ & 0.184 & 0.181 & & & -0.156 \\
\hline & $(0.176)$ & $(0.178)$ & $(0.201)$ & $(0.201)$ & & & $(0.247)$ \\
\hline \multirow[t]{2}{*}{ Age } & $-0.112^{\star \star \star}$ & $-0.104^{\star *}$ & $-0.095^{\star \star}$ & $-0.096 * \star$ & -0.083 & $-0.129 * \star$ & $-0.097 * \star$ \\
\hline & $(0.041)$ & $(0.041)$ & $(0.042)$ & $(0.042)$ & $(0.052)$ & $(0.056)$ & $(0.042)$ \\
\hline \multirow[t]{2}{*}{ Age Squared } & $0.001^{* *}$ & $0.001^{\star \star}$ & $0.001^{\star \star}$ & $0.001^{* *}$ & $0.001^{*}$ & $0.001^{*}$ & $0.001^{\star \star}$ \\
\hline & $(0.000)$ & $(0.000)$ & $(0.000)$ & $(0.000)$ & $(0.001)$ & $(0.001)$ & $(0.000)$ \\
\hline \multirow[t]{2}{*}{ Years of Education } & -0.043 & -0.045 & -0.044 & -0.043 & -0.067 & -0.026 & -0.046 \\
\hline & $(0.031)$ & $(0.031)$ & $(0.031)$ & $(0.031)$ & $(0.045)$ & $(0.035)$ & $(0.032)$ \\
\hline \multirow{2}{*}{$\begin{array}{l}\text { Total Household Labour Earnings } \\
\text { (00's of pa'anga) }\end{array}$} & $0.145^{\star \star}$ & $0.136^{\star \star}$ & $0.126^{\star \star}$ & 0.049 & 0.115 & $0.124^{*}$ & $0.119 * \star$ \\
\hline & $(0.057)$ & $(0.059)$ & $(0.059)$ & $(0.140)$ & $(0.081)$ & $(0.065)$ & $(0.058)$ \\
\hline \multirow[t]{2}{*}{ Household Labour Earnings Squared } & & & & 0.008 & & & \\
\hline & & & & $(0.012)$ & & & \\
\hline \multirow[t]{2}{*}{ Married Dummy } & -0.056 & -0.038 & -0.043 & -0.035 & -0.290 & 0.315 & 0.047 \\
\hline & $(0.256)$ & $(0.255)$ & $(0.260)$ & $(0.261)$ & $(0.347)$ & $(0.343)$ & $(0.260)$ \\
\hline \multirow[t]{2}{*}{ Born on Tongatapu Dummy } & $-0.534^{\star \star}$ & $-0.547^{\star \star}$ & $-0.554^{\star \star}$ & $-0.560 * \star$ & $-0.766^{\star \star \star}$ & -0.471 & $-0.551^{* \star}$ \\
\hline & $(0.233)$ & $(0.227)$ & $(0.225)$ & $(0.226)$ & $(0.269)$ & $(0.301)$ & $(0.223)$ \\
\hline \multirow[t]{2}{*}{ Height } & -0.001 & -0.003 & -0.003 & -0.003 & -0.006 & 0.006 & -0.003 \\
\hline & $(0.008)$ & $(0.009)$ & $(0.009)$ & $(0.009)$ & $(0.012)$ & $(0.013)$ & $(0.009)$ \\
\hline \multirow[t]{2}{*}{ Dummy for Currently Employed } & $0.367^{\star \star}$ & $0.367^{\star \star}$ & $0.370 * *$ & $0.414^{\star \star}$ & 0.151 & $0.703^{\star \star}$ & 0.006 \\
\hline & $(0.184)$ & $(0.180)$ & $(0.182)$ & $(0.186)$ & $(0.292)$ & $(0.282)$ & $(0.251)$ \\
\hline \multirow[t]{2}{*}{ Catholic } & & $1.164^{\star *}$ & $1.109 * \star$ & $1.123^{\star \star}$ & 0.544 & $1.259 * \star$ & $1.109 * \star$ \\
\hline & & $(0.531)$ & $(0.554)$ & $(0.557)$ & $(0.661)$ & $(0.631)$ & $(0.560)$ \\
\hline \multirow[t]{2}{*}{ Mormon } & & 0.603 & 0.521 & 0.552 & 0.254 & 0.485 & 0.500 \\
\hline & & $(0.639)$ & $(0.646)$ & $(0.650)$ & $(0.746)$ & $(0.722)$ & $(0.647)$ \\
\hline \multirow[t]{2}{*}{ Protestant } & & 0.672 & 0.674 & 0.706 & 0.119 & $0.926^{\star}$ & 0.679 \\
\hline & & $(0.423)$ & $(0.457)$ & $(0.462)$ & $(0.579)$ & $(0.514)$ & $(0.462)$ \\
\hline \multirow[t]{2}{*}{ Currently Smoke Dummy } & & & $-0.599 * \star$ & $-0.608^{\star *}$ & $-0.710 * \star \star$ & 0.482 & $-0.721 * \star \star$ \\
\hline & & & $(0.250)$ & $(0.251)$ & $(0.249)$ & $(0.835)$ & $(0.259)$ \\
\hline \multirow[t]{2}{*}{ Binge Drinker Dummy } & & & 0.025 & 0.023 & 0.078 & 0.123 & 0.064 \\
\hline & & & $(0.098)$ & $(0.097)$ & $(0.100)$ & $(0.212)$ & $(0.100)$ \\
\hline \multirow[t]{2}{*}{ Very Good Self-reported health dummy } & & & 0.189 & 0.194 & 0.436 & -0.084 & 0.160 \\
\hline & & & $(0.200)$ & $(0.200)$ & $(0.273)$ & $(0.290)$ & $(0.199)$ \\
\hline \multirow[t]{2}{*}{ Employed ${ }^{\star}$ Female } & & & & & & & $0.715^{\star *}$ \\
\hline & & & & & & & $(0.362)$ \\
\hline \multirow[t]{2}{*}{ Currently Smokes*Female } & & & & & & & 1.060 \\
\hline & & & & & & & $(0.920)$ \\
\hline \multirow[t]{2}{*}{ Constant } & $22.686^{\star \star \star}$ & $22.240^{\star \star \star}$ & $22.068^{\star \star \star}$ & $22.132^{\star \star \star}$ & $23.154^{\star \star \star}$ & $21.043^{\star \star \star}$ & $22.400^{\star \star \star}$ \\
\hline & $(1.550)$ & $(1.630)$ & $(1.640)$ & $(1.626)$ & $(2.081)$ & $(1.987)$ & $(1.624)$ \\
\hline Observations & 632 & 632 & 630 & 630 & 302 & 328 & 630 \\
\hline R-squared & 0.09 & 0.10 & 0.11 & 0.11 & 0.14 & 0.13 & 0.12 \\
\hline
\end{tabular}

Robust standard errors in parentheses, Clustered at Household Level

* significant at 10\%; ** significant at 5\%; ** significant at $1 \%$ 


\section{TABLE 2: TEST FOR RANDOMIZATION}

Comparison of Ex-ante characteristics of principal applicants, spouse, children >= 15 in successful and unsuccessful ballots

\begin{tabular}{lccc}
\hline & \multicolumn{2}{c}{$\begin{array}{c}\text { Sample Means } \\
\text { APPLICANTS } \\
\text { Successful } \\
\text { Bnsuccessful } \\
\text { Ballots }\end{array}$} & $\begin{array}{c}\text { T-test } \\
\text { of equality } \\
\text { of means } \\
\text { p-value }\end{array}$ \\
\hline Age & 31.0 & 31.2 & 0.83 \\
Years of schooling & 10.8 & 10.1 & 0.15 \\
Proportion male & 0.49 & 0.55 & 0.08 \\
Proportion born on Tongatapu & 0.79 & 0.78 & 0.86 \\
Proportion who had been to NZ before 2000 & 0.48 & 0.58 & 0.15 \\
Proportion who are married & 0.58 & 0.63 & 0.37 \\
Height (Age >= 18) & 170.9 & 168.3 & 0.07 \\
Income in 2003/before moving & 74.9 & 69.3 & 0.64 \\
Employment in 2003/before moving & 0.50 & 0.43 & 0.20 \\
Catholic & 0.13 & 0.15 & 0.79 \\
Mormon & 0.11 & 0.09 & 0.71 \\
Protestant & 0.69 & 0.71 & 0.74 \\
Total Sample Size & & & \\
\hline Test statistics account for clustering at the household & $\mathbf{2 3 6}$ & $\mathbf{1 4 9}$ & \\
\hline
\end{tabular}

Test statistics account for clustering at the household level 
TABLE 3: SAMPLE MEANS OF MENTAL HEALTH SCORE

\begin{tabular}{lccc}
\hline & Observations & $\begin{array}{c}\text { Mental Health } \\
(5-25: 25=\text { best })\end{array}$ & $\begin{array}{c}\text { Very Good v. Good/Average } \\
\text { Self-Reported Health Status }\end{array}$ \\
\hline APPLICANTS & 385 & 19.9 & 0.368 \\
Successful Ballots & 236 & 20.3 & 0.412 \\
$\quad$ Migrants & 128 & 21.9 & 0.586 \\
$\quad$ Non-migrants & 108 & 19.5 & 0.324 \\
Unsuccessful Ballots & 149 & 19.9 & 0.362 \\
NON-APPLICANTS & 122 & 20.5 & 0.377 \\
T-tests of equality of means & & \\
Successful Ballots vs Unsuccessful Ballots & 0.25 & 0.33 \\
Migrants vs Non-migrant Successful Ballots & & 0.00 \\
& & & \\
Migrants vs Unsuccessful ballots & 0.00 & 0.00 \\
Pure Experimental Estimators of the Gain in Income from Migration & \\
Intention-to-treat effect & 0.40 & 0.05 \\
Treatment-on-treated effect - Non-Adjusted & 1.98 & 0.22 \\
\hline
\end{tabular}

Test statistics account for clustering at the household level 
TABLE 4: REGRESSION-BASED EXPERIMENTAL ESTIMATES

Dependent Variable: Mental Health Score on 5-25 Scale (25 = best)

\begin{tabular}{|c|c|c|c|c|c|c|}
\hline & $\begin{array}{l}(1) \\
\text { OLS }\end{array}$ & $\begin{array}{l}\text { (2) } \\
\text { OLS }\end{array}$ & $\begin{array}{l}\text { (3) } \\
\text { IV }\end{array}$ & $\begin{array}{l}\text { (4) } \\
\text { IV }\end{array}$ & $\begin{array}{c}\text { (5) } \\
\text { IV-males }\end{array}$ & $\begin{array}{c}(6) \\
\text { IV-females }\end{array}$ \\
\hline Ballot Success Dummy & $\begin{array}{c}0.399 \\
(0.353)\end{array}$ & $\begin{array}{c}0.443 \\
(0.332)\end{array}$ & & & & \\
\hline Migration Dummy & & & $\begin{array}{c}1.190 \\
(1.022)\end{array}$ & $\begin{array}{l}1.307 \\
(0.916)\end{array}$ & $\begin{array}{c}0.928 \\
(1.205)\end{array}$ & $\begin{array}{l}1.807^{*} \\
(0.985)\end{array}$ \\
\hline Migration*Female Dummy & & & & & & \\
\hline Female Dummy & & $\begin{array}{c}0.430 \\
(0.272)\end{array}$ & & $\begin{array}{c}0.427 \\
(0.266)\end{array}$ & & \\
\hline Married Dummy & & $\begin{array}{l}-0.203 \\
(0.513)\end{array}$ & & $\begin{array}{l}-0.236 \\
(0.505)\end{array}$ & $\begin{array}{l}-0.037 \\
(0.708)\end{array}$ & $\begin{array}{l}-0.462 \\
(0.574)\end{array}$ \\
\hline Age & & $\begin{array}{l}-0.024 \\
(0.030)\end{array}$ & & $\begin{array}{l}-0.021 \\
(0.029)\end{array}$ & $\begin{array}{l}-0.031 \\
(0.035)\end{array}$ & $\begin{array}{l}-0.009 \\
(0.036)\end{array}$ \\
\hline Years of Education & & $\begin{array}{l}-0.067 \\
(0.047)\end{array}$ & & $\begin{array}{l}-0.068 \\
(0.046)\end{array}$ & $\begin{array}{l}-0.083 \\
(0.066)\end{array}$ & $\begin{array}{l}-0.063 \\
(0.049)\end{array}$ \\
\hline Born on Tongatapu Dummy & & $\begin{array}{l}-0.226 \\
(0.403)\end{array}$ & & $\begin{array}{l}-0.212 \\
(0.395)\end{array}$ & $\begin{array}{l}0.255 \\
(0.575)\end{array}$ & $\begin{array}{l}-0.521 \\
(0.578)\end{array}$ \\
\hline Height & & $\begin{array}{c}0.001 \\
(0.016)\end{array}$ & & $\begin{array}{c}0.000 \\
(0.016)\end{array}$ & $\begin{array}{l}-0.005 \\
(0.018)\end{array}$ & $\begin{array}{l}0.015 \\
(0.026)\end{array}$ \\
\hline Catholic & & $\begin{array}{l}2.105^{\star *} \\
(0.842)\end{array}$ & & $\begin{array}{l}2.099 * * \\
(0.826)\end{array}$ & $\begin{array}{c}0.839 \\
(1.296)\end{array}$ & $\begin{array}{c}2.962^{* * *} \\
(0.894)\end{array}$ \\
\hline Mormon & & $\begin{array}{l}1.425^{*} \\
(0.822)\end{array}$ & & $\begin{array}{l}1.452^{\star} \\
(0.800)\end{array}$ & $\begin{array}{c}0.138 \\
(1.019)\end{array}$ & $\begin{array}{l}2.335^{\star *} \\
(1.019)\end{array}$ \\
\hline Protestant & & $\begin{array}{c}0.715 \\
(0.620)\end{array}$ & & $\begin{array}{c}0.727 \\
(0.606)\end{array}$ & $\begin{array}{l}-0.500 \\
(0.943)\end{array}$ & $\begin{array}{l}1.549 * * \\
(0.789)\end{array}$ \\
\hline Past income & & $\begin{array}{l}-0.001 \\
(0.001)\end{array}$ & & $\begin{array}{l}-0.002 \\
(0.001)\end{array}$ & $\begin{array}{l}-0.001 \\
(0.002)\end{array}$ & $\begin{array}{l}-0.002 \\
(0.002)\end{array}$ \\
\hline Constant & $\begin{array}{c}19.90 * \star \star \\
(0.26)\end{array}$ & $\begin{array}{c}20.34^{\star \star *} \\
(2.90)\end{array}$ & $\begin{array}{c}19.90 * \star \star \\
(0.26)\end{array}$ & $\begin{array}{c}20.35^{\star \star \star} \\
(2.83)\end{array}$ & $\begin{array}{c}22.40^{\star \star *} \\
(2.55)\end{array}$ & $\begin{array}{c}17.66^{\star \star \star} \\
(4.37)\end{array}$ \\
\hline $\begin{array}{l}\text { First stage F-statistic on } \\
\text { instrument: }\end{array}$ & & & 47.68 & 48.50 & 35.31 & 44.86 \\
\hline $\begin{array}{l}\text { Observations } \\
\text { R-squared }\end{array}$ & $\begin{array}{c}385 \\
0\end{array}$ & $\begin{array}{l}364 \\
0.12\end{array}$ & 385 & 364 & 171 & 193 \\
\hline
\end{tabular}

Robust standard errors in parentheses, Clustered at Household Level

Columns 1 to 4 and 7 are for combined sample of males and females.

Ballot Success is used as an instrument for Migration, and Ballot Success*Female for Migration*Female.

* significant at $10 \%$; ** significant at $5 \%$; *** significant at $1 \%$ 
TABLE 5: IV ESTIMATES OF EXPERIMENTAL IMPACT FOR DIFFERENT THRESHOLDS Dependent Variable: ML IV Probit Models on Various Thresholds

Marginal Effects and Standard Errors for Marginal Effects Are Presented

\begin{tabular}{|c|c|c|c|}
\hline & (1) & (2) & (3) \\
\hline & $<18$ & $<19$ & $<20$ \\
\hline Migration Dummy & $\begin{array}{c}-0.171^{\star \star \star} \\
(0.045)\end{array}$ & $\begin{array}{c}-0.306^{\star \star \star} \\
(0.066)\end{array}$ & $\begin{array}{c}-0.372^{\star \star \star} \\
(0.109)\end{array}$ \\
\hline Female & $\begin{array}{c}0.025 \\
(0.052)\end{array}$ & $\begin{array}{c}-0.062 \\
(0.067)\end{array}$ & $\begin{array}{c}-0.004 \\
(0.067)\end{array}$ \\
\hline Married Dummy & $\begin{array}{c}0.049 \\
(0.082)\end{array}$ & $\begin{array}{c}0.088 \\
(0.103)\end{array}$ & $\begin{array}{c}0.058 \\
(0.124)\end{array}$ \\
\hline Age & $\begin{array}{c}0.006 \\
(0.005)\end{array}$ & $\begin{array}{c}0.000 \\
(0.006)\end{array}$ & $\begin{array}{l}-0.001 \\
(0.007)\end{array}$ \\
\hline Years of Education & $\begin{array}{c}0.002 \\
(0.009)\end{array}$ & $\begin{array}{c}0.010 \\
(0.012)\end{array}$ & $\begin{array}{l}0.025^{*} \\
(0.014)\end{array}$ \\
\hline Born on Tongatapu Dummy & $\begin{array}{l}-0.046 \\
(0.070)\end{array}$ & $\begin{array}{c}0.005 \\
(0.078)\end{array}$ & $\begin{array}{c}0.044 \\
(0.097)\end{array}$ \\
\hline Height & $\begin{array}{l}-0.002 \\
(0.003)\end{array}$ & $\begin{array}{c}0.000 \\
(0.004)\end{array}$ & $\begin{array}{c}0.002 \\
(0.004)\end{array}$ \\
\hline Catholic & $\begin{array}{c}-0.179 * \star \star \\
(0.047)\end{array}$ & $\begin{array}{c}-0.258^{\star \star} \\
(0.108)\end{array}$ & $\begin{array}{l}-0.199 \\
(0.187)\end{array}$ \\
\hline Mormon & $\begin{array}{c}-0.141^{\text {** }} \\
(0.067)\end{array}$ & $\begin{array}{l}-0.187 \\
(0.125)\end{array}$ & $\begin{array}{l}-0.247 \\
(0.155)\end{array}$ \\
\hline Protestant & $\begin{array}{l}-0.114 \\
(0.102)\end{array}$ & $\begin{array}{l}-0.168 \\
(0.158)\end{array}$ & $\begin{array}{l}-0.055 \\
(0.170)\end{array}$ \\
\hline Past income & $\begin{array}{c}0.000 \\
(0.000)\end{array}$ & $\begin{array}{c}0.000 \\
(0.000)\end{array}$ & $\begin{array}{c}0.000 \\
(0.000)\end{array}$ \\
\hline Observations & 364 & 364 & 364 \\
\hline
\end{tabular}


TABLE 6: IV QUANTILE REGRESSION EXPERIMENTAL ESTIMATES (CH METHOD)

Dependent Variable: Mental Health Score on 5-25 Scale (25 = best)

\begin{tabular}{lccc}
\hline & $(1)$ & $(2)$ & $(3)$ \\
& 25 th Pctile & 50 th Pctile & 75 th Pctile \\
\hline Migration Dummy & 2.810 & 1.100 & 1.050 \\
& $(1.447)$ & $(1.199)$ & $(0.875)$ \\
Female Dummy & $0.25-3.48]$ & {$[-0.28-2.68]$} & {$[0.13-2.26]$} \\
Married Dummy & 0.335 & -0.234 & 0.652 \\
& $(0.584)$ & $(0.515)$ & $(0.467)$ \\
Age & -0.699 & 0.271 & 0.446 \\
& $(0.615)$ & $(0.902)$ & $(0.821)$ \\
Years of Education & -0.025 & -0.049 & -0.009 \\
& $(0.033)$ & $(0.051)$ & $(0.043)$ \\
Born on Tongatapu Dummy & -0.142 & -0.039 & -0.120 \\
& $(0.083)$ & $(0.063)$ & $(0.076)$ \\
Height & -0.003 & -0.266 & -0.340 \\
& $(0.671)$ & $(0.812)$ & $(0.632)$ \\
Catholic & -0.004 & -0.027 & -0.004 \\
& $(0.043)$ & $(0.036)$ & $(0.023)$ \\
Mormon & 1.612 & 3.559 & 1.341 \\
& $(1.339)$ & $(1.657)$ & $(1.446)$ \\
Protestant & 1.379 & 2.801 & 0.364 \\
Past income & $(1.283)$ & $(1.562)$ & $(1.498)$ \\
& 0.408 & 1.757 & 0.001 \\
Observations & $(0.876)$ & $(1.340)$ & $(1.321)$ \\
Robust bootstrapped standard errors in parentheses, Clustered at Household Level \\
Ballot Success is used as an instrument for Migration & & -0.002 \\
Significance levels are derived using the percentile method & & \\
* significant at 10\%; ** significant at 5\%; *** significant at $1 \% ; 80 \%$ confidence interval in brackets
\end{tabular}


TABLE 7: TREATMENT EFFECT OF MIGRATION ON CORRELATES OF MENTAL HEALTH

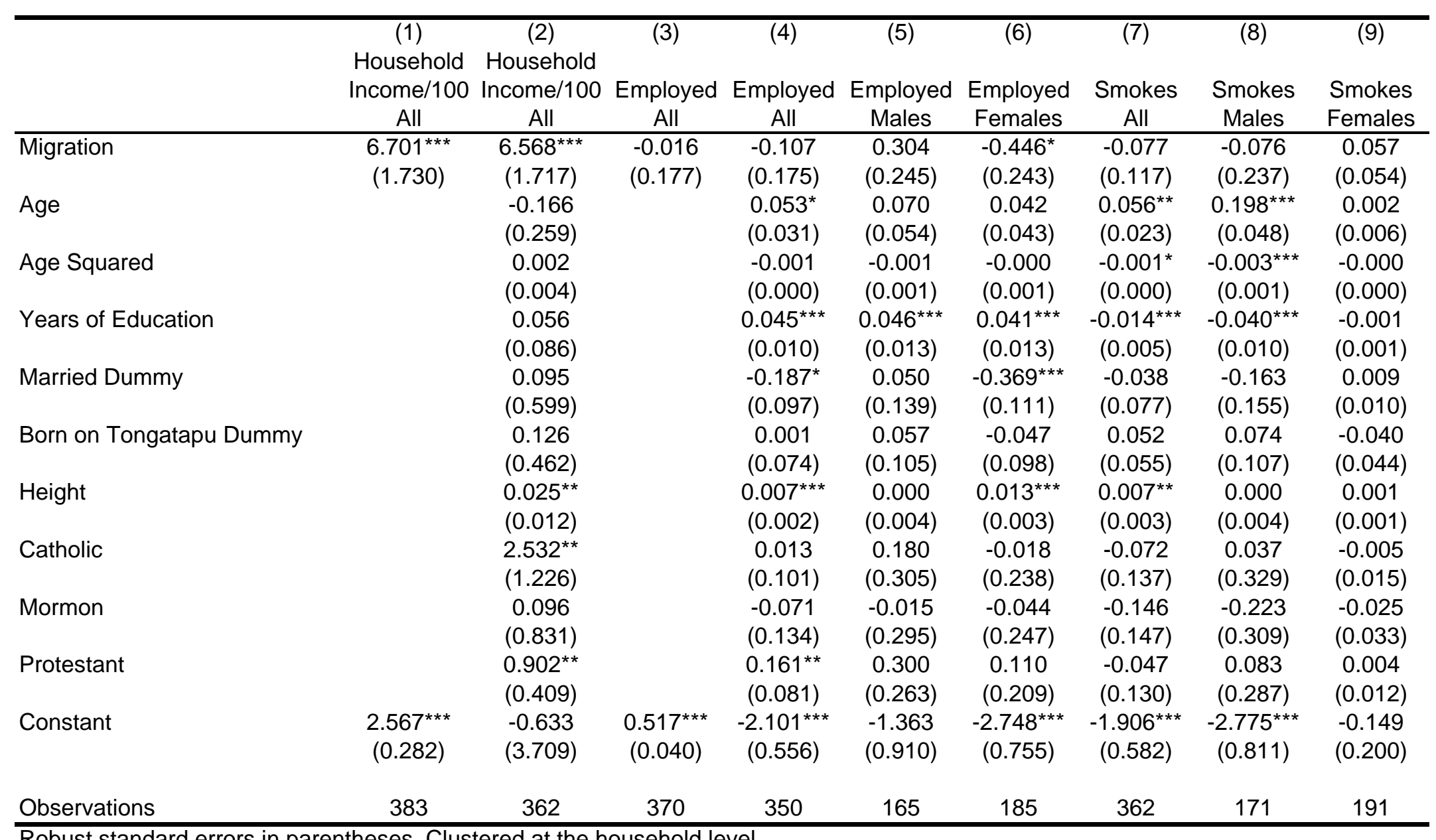

Robust standard errors in parentheses. Clustered at the household level.

* significant at 10\%; ** significant at $5 \%$; ** significant at $1 \%$ 


\section{TABLE 8: REASONS FOR APPLYING TO MIGRATE}

Proportion of Tongans in Tonga saying reason is very important

\begin{tabular}{|c|c|c|c|c|c|c|}
\hline & \multicolumn{3}{|c|}{ By Mental Health Score } & \multicolumn{3}{|c|}{ By Sex } \\
\hline & $<19$ & 20 to 25 & $p$-value & Male & Female & p-value \\
\hline To be with family members already in NZ & 0.815 & 0.662 & 0.055 & 0.652 & 0.800 & 0.058 \\
\hline To earn money for school fees in Tonga & 0.037 & 0.039 & 0.955 & 0.061 & 0.015 & 0.180 \\
\hline So my children can attend school in NZ & 0.327 & 0.671 & 0.000 & 0.581 & 0.474 & 0.247 \\
\hline To earn money to start a business in Tonga & 0.000 & 0.026 & 0.236 & 0.015 & 0.015 & 0.991 \\
\hline To earn money to build a better house in Tonga & 0.037 & 0.052 & 0.691 & 0.076 & 0.015 & 0.100 \\
\hline Better public services such as health care in NZ & 0.796 & 0.831 & 0.615 & 0.758 & 0.877 & 0.079 \\
\hline To earn higher wages in NZ & 0.463 & 0.584 & 0.173 & 0.591 & 0.477 & 0.194 \\
\hline To earn money to pay for social responsabilities in my home village & 0.148 & 0.091 & 0.315 & 0.106 & 0.123 & 0.762 \\
\hline Better social life & 0.704 & 0.351 & 0.000 & 0.439 & 0.554 & 0.193 \\
\hline Less cultural restrictions on what I can do and cannot do & 0.000 & 0.039 & 0.145 & 0.000 & 0.046 & 0.079 \\
\hline Sample Size & 54 & 77 & & 66 & 65 & \\
\hline
\end{tabular}

Note: $p$-value is for a t-test of equality of proportions between the two groups. 